Sílvia M. V. Fernandes • José L. F. C. Lima

António O. S. S. Rangel

\title{
Spectrophotometric flow injection determination of total phosphorus in beer using on-line UV/thermal induced digestion
}

\begin{abstract}
A flow injection system for the automatic determination of total phosphorus in beer is described. The developed manifold uses a two-stage photooxidation/thermal digestion procedure together with oxidizing and hydrolyzing reagents to convert all forms of phosphorus compounds to orthophosphate. Polyphosphates are hydrolyzed by acid and heat, and organo-phosphates are digested by UV-catalyzed peroxodisulfate oxidation. The orthophosphate formed is then spectrophotometrically determined by the phosphomolybdenum blue reaction, using stannous chloride as reducing agent. The results obtained for a set of 19 beer samples (with concentrations from 120 to $735 \mathrm{mg} \mathrm{P} / \mathrm{L}$ ) were in good agreement with the reference method, the maximum relative deviation found being $4.7 \%$. Relative standard deviations for ten consecutive determinations were lower than $1.5 \%$, and a detection limit of $1 \mathrm{mg} \mathrm{P} / \mathrm{L}$ was achieved.
\end{abstract}

\section{Introduction}

Inorganic and organic phosphorus from brewing water have an important impact on beer flavor and physical appearance. The measurement of its concentration in all phases of beer production can be used to help track metabolic products of fermentation and correlate beer flavor trends [1].

Organically bound phosphates, condensed phosphates and orthophosphates are collectively defined as total phosphorus (TP) [2]. Prior to analysis, TP must be converted

S. M. V. Fernandes · A. O. S. S. Rangel ( $₫)$

Escola Superior de Biotecnologia,

Universidade Católica Portuguesa,

Rua Dr. António Bernardino de Almeida,

P-4200-072 Porto, Portugal

e-mail: rangel@esb.ucp.pt

J. L. F. C. Lima

CEQUP/Departamento de Química-Física,

Faculdade de Farmácia do Porto, Rua Aníbal Cunha 164,

P-4050 Porto, Portugal into a readily analyzable form, for example orthophosphate. This is accomplished, in water, wine, beer and beverage analysis, by wet or dry digestion procedures [3-5]. The main disadvantages of these methods is that they are relatively slow and require considerable operator care. As a result of this, they are ill suited to TP determination for real-time process control or continuous discharge monitoring. Therefore, the development of automatic procedures for continuous digestion and analysis is desirable.

On-line digestion with flow injection analysis has been recognized as a technique for rapid TP determination. Benson and McKelvie [6] reported the determination of TP in waters and waste waters by on-line microwave-induced digestion. Woo and Maher [7] determined TP in turbid waters using alkaline potassium peroxodisulfate digestion, with good recoveries for various phosphorus compounds, organic and inorganic, for distilled and lake water. Later on, Benson et al. [8] reported the determination of TP in waters and waste waters by on-line UV/thermal induced digestion and considered this approach more suitable for on-line monitoring applications than the microwave digestion methods previously reported, because of the low power requirements of this procedure.

In this work, we propose a flow injection method for TP determination in a relatively complex matrix: beer. The developed method uses a two-stage photooxidation/ thermal digestion procedure together with oxidizing and hydrolyzing reagents to convert all forms of phosphorus compounds to orthophosphate. In this procedure, polyphosphates are hydrolyzed with acid and heat and organophosphates are digested by UV-catalyzed peroxodisulfate oxidation. The orthophosphate formed is then spectrophotometrically determined by the phosphomolybdenum blue reaction, using stannous chloride as reducing agent.

\section{Experimental}

Reagents and solutions

All chemicals were of analytical reagent grade, and deionized water with a specific conductance less than $0.1 \mu \mathrm{S} / \mathrm{cm}$ was used throughout. 
For the on-line digestion procedure, a $2 \mathrm{M}$ sulfuric acid solution was prepared by suitable dilution of conc. sulfuric acid $(\mathrm{d}=1.84$; $97 \%$ ), and a $6 \mathrm{~g} / \mathrm{L}$ potassium peroxodisulfate solution was prepared by dissolving $3 \mathrm{~g}$ of the solid in $500 \mathrm{~mL}$ of water. This solution was prepared every week.

For the color reaction, a $0.15 \mathrm{M}$ sulfuric acid solution was used as carrier, prepared by suitable dilution of conc. sulfuric acid.

The color reagent, a $9.4 \mathrm{~g} / \mathrm{L}$ ammonium molybdate solution, was prepared by dissolving $5.0 \mathrm{~g}$ of ammonium heptamolybdatetetrahydrate in water. While mixing, $18 \mathrm{~mL}$ of conc. sulfuric acid was added and the volume was made up to $500 \mathrm{~mL}$. This solution was about $0.65 \mathrm{M}$ in sulfuric acid and was prepared weekly.

For preparing the stannous chloride solution, $14 \mathrm{~mL}$ of conc. sulfuric acid was mixed with water; $0.1 \mathrm{~g}$ of stannous chloride dihydrate and $1 \mathrm{~g}$ of hydrazinium sulfate were dissolved in this solution, and the volume was made up to $500 \mathrm{~mL}$. This solution was prepared daily, and contained $0.17 \mathrm{~g}$ of stannous chloride and $2 \mathrm{~g}$ of hydrazinium sulfate per litre. Its concentration in sulfuric acid was $0.5 \mathrm{M}$.

The phosphorus stock solution ( $2 \mathrm{~g} \mathrm{P} / \mathrm{L})$ was obtained by dissolving $8.788 \mathrm{~g}$ of potassium dihydrogen phosphate in $1 \mathrm{~L}$ of water. An intermediate working solution containing $0.1 \mathrm{~g} \mathrm{P} / \mathrm{L}$ was prepared every week by diluting $50.0 \mathrm{~mL}$ of the stock solution to $1 \mathrm{~L}$. Working standard solutions in the range $2.00-20.0 \mathrm{mg} \mathrm{P} / \mathrm{L}$ were prepared daily by dilution of the intermediate working solution with water.

For the recovery assays, stock solutions $(1 \mathrm{~g} \mathrm{P} / \mathrm{L})$ of sodium pyrophosphate and sodium phenylphosphate were prepared by dissolving, respectively, $3.60 \mathrm{~g}$ and $4.10 \mathrm{~g}$ of the solid in $500 \mathrm{~mL}$ of water. Stock solution of trimethylphosphate $(1 \mathrm{~g} \mathrm{P} / \mathrm{L})$ was prepared by diluting $1.86 \mathrm{~mL}$ of sodium trimethylphosphate $(\mathrm{d}=$ $1.214 ;>98 \%$ ) to $500 \mathrm{~mL}$ with water. Working standard solutions containing $10 \mathrm{mg} \mathrm{P} / \mathrm{L}$ were prepared daily by dilution of each stock solution with water.

For the reference procedure, the molybdovanadate reagent was prepared by dissolving $40 \mathrm{~g}$ of ammonium heptamolybdate-tetrahydrate in $400 \mathrm{~mL}$ of hot water and cooling. In a separate vessel, $2 \mathrm{~g}$ of ammonium monovanadate was dissolved in $250 \mathrm{~mL}$ of hot water and cooled, and $250 \mathrm{~mL}$ of $70 \%$ perchloric acid was added to this solution. Gradually, the molybdate solution was added to the vanadate solution with stirring, and diluted to $2 \mathrm{~L}$.

Working standard solutions were prepared in the range of 5.00-20.0 $\mathrm{mg} \mathrm{P} / \mathrm{L}$ from the same intermediate working solution described for the FIA procedure.

Beer samples were degassed in an ultrasonic bath for $10 \mathrm{~min}$, and diluted 50 fold prior to their introduction into the flow injection system.

\section{Apparatus and flow injection system}

In the flow injection system, all the solutions were propelled by Gilson Minipuls 3 peristaltic pumps and PVC Gilson propelling tubes. The solutions coming out from the digestion unit were injected into the manifold with a Rheodyne type 5020 six-port rotary injection valve. Omnifit PTFE tubing $(0.8 \mathrm{~mm}$ i.d.) with Gilson end-fittings and connectors linked the components of the manifold. Perspex Y-shaped joints were used as confluences. An Hitachi 100-40 spectrophotometer (wavelength set at $710 \mathrm{~nm}$ ), equipped with a Hellma 178.713 flow cell $(8 \mu \mathrm{L}$ of optical volume) and connected to a Kipp \& Zonen BD 111 chart recorder was used as detection system.

The UV digestion apparatus consisted of a $4 \mathrm{~m}$ long Omnifit PTFE tubing ( $0.8 \mathrm{~mm}$ i.d.) tightly wounded directly around the UV source tube $(15 \mathrm{~W})$ to form a spiral reactor. The reactor was then wrapped by an aluminium foil from the outer side. The foil prevented operator exposure to UV radiation and, in addition, it reflected nonabsorbed UV energy back into the flowing solution to increase decomposition efficiency.

The thermal digestion apparatus consisted of a $2 \mathrm{~m}$ long Omnifit PTFE tubing (0.8 $\mathrm{mm}$ i.d.) helically coiled and submerged in a Julabo VC thermostatic bath with temperature set at $90^{\circ} \mathrm{C}$.

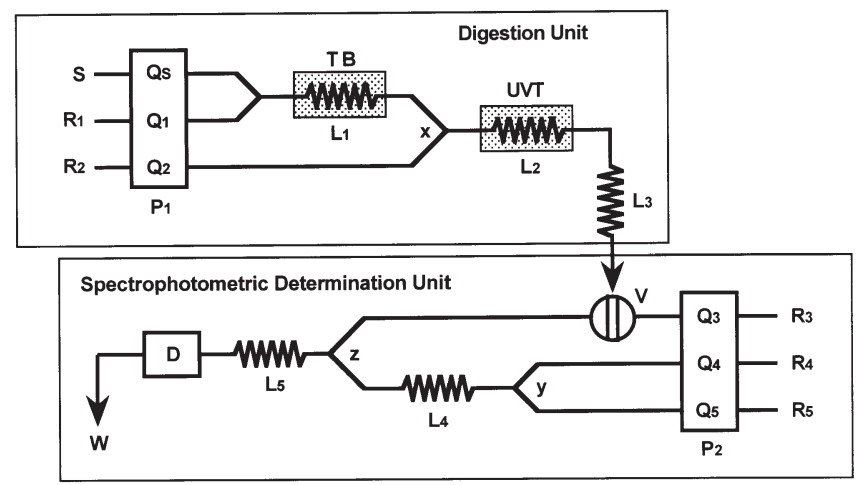

Fig. 1 Flow injection manifold developed for the determination of total phosphorus in beer samples: $D$ - detector (spectrophotometer); $L i$ - tube lengths ( $L 1=200 ; L 2=400 ; L 3=100 ; L 4=100$; $L 5=200 \mathrm{~cm}) ; Q i-$ flow rates $(\mathrm{Qs}=Q 1=Q 2=0.23 ; Q 3=Q 4=$ $Q 5=0.60 \mathrm{~mL} / \mathrm{min}) ; P i-$ peristaltic pumps; $R i-$ reagent solutions $\left(R I=2 \mathrm{M} \mathrm{H}_{2} \mathrm{SO}_{4} ; R 2=6 \mathrm{~g} / \mathrm{L}\right.$ potassium peroxodisulfate; $R 3=$ $0.25 \mathrm{M} \mathrm{H}_{2} \mathrm{SO}_{4} ; R 4=9.4 \mathrm{~g} / \mathrm{L}$ ammonium molybdate, $0.65 \mathrm{M}$ $\mathrm{H}_{2} \mathrm{SO}_{4} ; R 5=0.17 \mathrm{~g} / \mathrm{L}$ stannous chloride, $2 \mathrm{~g} / \mathrm{L}$ hydrazinium sulfate, $\left.0.5 \mathrm{M} \mathrm{H}_{2} \mathrm{SO}_{4}\right) ; S$ - standards or beer samples; $T B$ - thermostatic bath $\left(90^{\circ} \mathrm{C}\right) ; U V T$ - ultraviolet radiation tube; $V$ - injection volume $(40 \mu \mathrm{L}) ; W$ - waste; $x, y, z$ - confluence points

Flow injection procedure

A flow injection manifold was designed to carry out, inside the flow tubes, the digestion of the sample and the subsequent color reaction, with the minimum sample pretreatment. To achieve this purpose, the flow injection manifold consisted of two distinct parts, being one of them the UV/thermal digestion unit and the other the color development manifold (Fig. 1).

In the digestion unit, condensed phosphates are hydrolyzed by acid and heat, and organophosphates are digested by UV-catalyzed peroxodisulfate oxidation. To accomplish these purposes, phosphorus standards or beer diluted samples (S) were continuously mixed on-line with a stream of $2 \mathrm{M} \mathrm{H}_{2} \mathrm{SO}_{4}\left(\mathrm{R}_{1}\right)$ and the resulting solution flowed to a $2 \mathrm{~m}$ coil $\left(\mathrm{L}_{1}\right)$ placed in a thermostatic bath with the temperature set at $90{ }^{\circ} \mathrm{C}$. Afterwards, the heated solution merged with peroxodisulfate solution $\left(\mathrm{R}_{2}\right)$ and flowed through the $4 \mathrm{~m}$ coil $\left(\mathrm{L}_{2}\right)$ wrapped around the UV tube. An aliquot $(40 \mu \mathrm{L})$ of the digested solution was then injected into $\mathrm{a}_{2} \mathrm{SO}_{4}$ carrier stream and merged, at confluence $\mathrm{z}$, with the color $\left(\mathrm{R}_{4}\right)$ and reducing $\left(\mathrm{R}_{5}\right)$ reagents, previously mixed at confluence $y$. The resulting phosphomolybdenum blue was then monitored at $710 \mathrm{~nm}$.

\section{Reference method}

The colorimetric procedure usually recommended for total phosphorus determination in water, beverages and wine [3-5] was used as reference method. Samples were incinerated at $550-600{ }^{\circ} \mathrm{C}$, after previous evaporation to dryness on a hot plate. Ashes were recovered in nitric acid and this solution was then diluted with water to a certain volume, which was determined by a trial and error approach. Afterwards, the color reagent (molybdovanadate) was added to $10 \mathrm{~mL}$ of sample solution in a $100 \mathrm{~mL}$ volumetric flask and diluted to volume with water. The absorbance was then measured at $400 \mathrm{~nm}$, and the phosphorus content of the samples determined from a previously established calibration plot. 


\section{Results and discussion}

Optimization of the manifold

After preliminary experiments to select approximate values for each parameter, an univariate optimization procedure was followed. As the flow system is divided in two different units, each unit parameter was optimized separately. The optimum values found are presented in Fig. 1.

Study of the flow injection digestion unit. A series of digestion recovery studies were conducted to establish the reagent composition and manifold configuration for achieving quantitative conversion of both organic and condensed phosphorus material to orthophosphate. The results of these assays are summarized in Table 1. All percentage conversion values were calculated with respect to a calibration curve constructed from a series of potassium dihydrogen phosphate standards.

The results summarized in Table 1 show that, as the $\mathrm{H}_{2} \mathrm{SO}_{4}$ concentration was increased up to $2 \mathrm{M}$, conversion of the three phosphorus compounds also increased, with special incidence on the pyrophosphate recovery (from 40.6 to $85.4 \%$ ). Further increases in the $\mathrm{H}_{2} \mathrm{SO}_{4}$ concentration had little or no effect on the conversion percentages, and led to double peaks probably because of a pronounced $\mathrm{pH}$ gradient, with a very high $\mathrm{pH}$ at the centre of the injected plug. Concerning the peroxodisulfate solution, it can be seen that increasing concentrations of this reagent up to $6 \mathrm{~g} / \mathrm{L}$ slightly improved $(2.7 \%)$ pyrophosphate recoveries, but strongly increased $(12.6 \%)$ conversion of trimethylphosphate. Increasing the peroxodisulfate concentration, although providing an improvement $(8.8 \%)$ of the phenylphosphate conversion, caused a slight suppression $(2.4 \%)$ of the conversion of pyrophosphate and a decrease $(6.2 \%)$ of sensitivity.

As pyrophosphate seemed to be the most difficult compound to convert, it was chosen as model compound to

Table 1 Recoveries of organic and condensed forms of phosphorus: reagent and residence time optimization. The standard deviations corresponding to 3 measurements are indicated between brackets

\begin{tabular}{|c|c|c|c|c|}
\hline \multirow[t]{2}{*}{ Parameter } & & \multicolumn{3}{|c|}{ Recovery percentage } \\
\hline & & $\begin{array}{l}\text { Phenyl- } \\
\text { phosphate }\end{array}$ & $\begin{array}{l}\text { Trimethyl- } \\
\text { phosphate }\end{array}$ & $\begin{array}{l}\text { Pyro- } \\
\text { phosphate }\end{array}$ \\
\hline \multirow[t]{3}{*}{$\mathrm{H}_{2} \mathrm{SO}_{4}$} & $1 \mathrm{M}$ & $82.8( \pm 0.1)$ & $78.6( \pm 0.3)$ & $40.6( \pm 0.1)$ \\
\hline & $2 \mathrm{M}$ & $99.8( \pm 0.2)$ & $95.7( \pm 0.1)$ & $85.4( \pm 0.1)$ \\
\hline & $4 \mathrm{M}$ & $101.5( \pm 0.3)$ & $91.3( \pm 4.1)$ & $86.9( \pm 4.4)$ \\
\hline \multirow{3}{*}{$\begin{array}{l}\text { Peroxo- } \\
\quad \text { disulfate }\end{array}$} & $4 \mathrm{~g} / \mathrm{L}$ & $92.5( \pm 0.0)$ & $92.2( \pm 1.2)$ & $87.3( \pm 1.2)$ \\
\hline & $6 \mathrm{~g} / \mathrm{L}$ & $95.0( \pm 0.7)$ & $104.8( \pm 0.7)$ & $90.0( \pm 0.8)$ \\
\hline & $8 \mathrm{~g} / \mathrm{L}$ & $103.8( \pm 1.1)$ & $105.1( \pm 0.1)$ & $87.6( \pm 0.1)$ \\
\hline \multirow{4}{*}{$\begin{array}{l}\text { Residence } \\
\text { time }\end{array}$} & $4 \mathrm{~min}$ & - & - & $84.5( \pm 0.8)$ \\
\hline & $5 \mathrm{~min}$ & - & - & $87.0( \pm 2.0)$ \\
\hline & $6 \mathrm{~min}$ & - & - & $90.8( \pm 1.8)$ \\
\hline & $12 \mathrm{~min}$ & - & - & $91.2( \pm 0.7)$ \\
\hline
\end{tabular}

accomplish optimization of the residence time. The residence time of the sample in the digestion unit was controlled by the selection of the flow-rates $\mathrm{Q}_{\mathrm{S}}, \mathrm{Q}_{1}$ and $\mathrm{Q}_{2}$. The results in Table 1 show that digestion recoveries increased significantly up to a residence time of $6 \mathrm{~min}$. Beyond this value, although there is a slight improvement in the conversion of pyrophosphate, the sampling rate largely decreased.

Study of the spectrophotometric determination manifold. Several system parameters were tested in order to achieve a compromise between the sensitivity of the analytical measurements, the linear working range for the determination and the sampling rate.

Since the color reaction used in this work has been widely studied in flow injection systems, both color reagent and reducing reagent concentrations were set on literature basis $[9,10]$.

An injection volume of $40 \mu \mathrm{L}$ was selected. Higher injection volumes produced an increase (about 30\%) of the magnitude of the spectrophotometric signals, but had the disadvantage of considerably lowering the sampling rate (from 40 to 30 samples per hour). On the other hand, the use of smaller injection volumes decreased the sensitivity by half.

A total flow rate of $1.8 \mathrm{~mL} / \mathrm{min}$ was selected as a compromise between the sampling rate and the sensitivity of the process. Flow rates $\mathrm{Q}_{4}$ and $\mathrm{Q}_{5}$ were made equal to $0.6 \mathrm{~mL} / \mathrm{min}$. Flow rate $\mathrm{Q}_{3}$ was studied within the range of $0.6-1.2 \mathrm{~mL} / \mathrm{min}$, maintaining a total flow rate of $1.8 \mathrm{~mL} /$ $\min$ and $\mathrm{Q}_{4}=\mathrm{Q}_{5}$. It was found that increasing $\mathrm{Q}_{3}$ flow rate led to poorer sensitivity because of the influence of the $\mathrm{pH}$ in the color development. So, a flow rate $\mathrm{Q}_{3}$ of $0.6 \mathrm{~mL} /$ min was chosen.

As the sensitivity of the spectrophotometric phosphate determination is strongly dependent on the acidity of the medium, and considering the acidity of the digestate injected into the system (approximately $0.67 \mathrm{M}$ ), a solution of $\mathrm{H}_{2} \mathrm{SO}_{4}$ was used as carrier stream $\left(\mathrm{R}_{3}\right)$ to avoid the influence on the analytical signal of differences of the refractive indices between both solutions (Schlieren effect) [11]. In order to select the $\mathrm{H}_{2} \mathrm{SO}_{4}$ concentration, different solutions were prepared within the range of $0.15-0.65 \mathrm{M}$. Low $\mathrm{H}_{2} \mathrm{SO}_{4}$ concentrations resulted in poor repeatability ( $\mathrm{RSD}=11.2 \%, \mathrm{n}=3)$ and significant baseline drift, as well as refraction index phenomena when standards or samples were injected; higher concentrations gave rise to low sensitivity. So, a $0.25 \mathrm{M} \mathrm{H}_{2} \mathrm{SO}_{4}$ solution was chosen as a compromise between baseline stability, repeatability and sensitivity. Nevertheless, a baseline drift still occurred (Fig. 2), probably due to accumulation of the colored complex in the flow cell walls, but did not affect the quality of the results.

The choice of the reactor length $\mathrm{L}_{5}$ was made according to the results obtained with tubes of 50, 100 and 200 $\mathrm{cm}$. Best sensitivity was achieved with a $200 \mathrm{~cm}$ reactor. To improve the mixing of solutions and consequently baseline stability, the coil was replaced by a knitted reactor. 


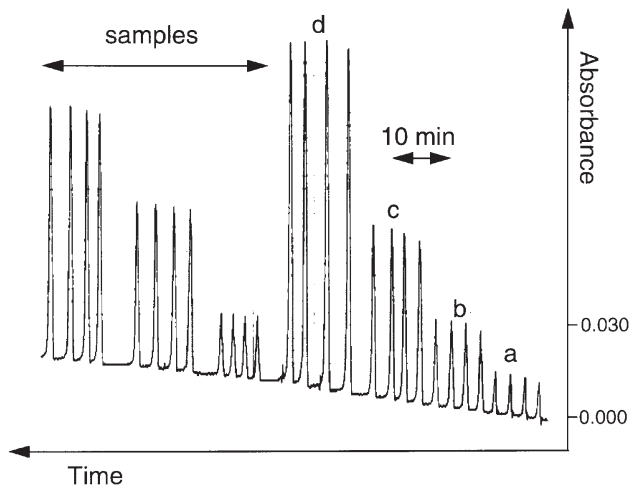

Fig. 2 Recorder output for the determination of total phosphorus in beer corresponding to injections of standards: (a) 2.00, (b) 5.00, (c) 10.00 and (d) $20.00 \mathrm{mg} \mathrm{P} / \mathrm{L}$, and samples

Under the optimized conditions of the FIA system, the detection limit of the methodology was calculated according to IUPAC recommendations [12], corresponding to three-times the standard deviation of the system background noise, to about $1 \mathrm{mg}$ P/L.

Analysis of beer samples. Nineteen diluted beer solutions (1:50) were aspirated into the developed flow injection manifold and the concentrations of total phosphorus were calculated by interpolation in the previously established calibration plots, with standards from 2 to $20 \mathrm{mg}$ P/L (typical calibration graph: absorbance $=2.3 \times 10^{-3}+1.4$ $\times 10^{-2} \times$ concentration). Every standard or beer solution was injected four times (Fig. 2). Concentration levels between 2.4 and $14.7 \mathrm{mg} \mathrm{P} / \mathrm{L}$ were found, corresponding to $120-735 \mathrm{mg} \mathrm{P} / \mathrm{L}$ in beer samples.

In order to assess the accuracy of the FIA results $\left(\mathrm{C}_{\mathrm{f}}\right)$, beer samples were also analyzed by the reference method $\left(\mathrm{C}_{\mathrm{r}}\right)$. There was a good agreement between the two methodologies, as can be perceived from the parameters of the regression equation: $C_{f}=4.29( \pm 7.06)+0.980$ $( \pm 0.021) \times \mathrm{C}_{\mathrm{r}}$; correlation coefficient $=0.999$. In parentheses are the confidence limits of the intercept and slope obtained with a 95\% significance level [13] for 17 degrees of freedom. These values show that there is no evidence for systematic differences between the two sets of results.

The precision of the FIA methodology was determined from ten consecutive injections of two beer sample solutions; relative standard deviations of 0.49 and $1.45 \%$ were observed for samples with concentrations of 320 and $167 \mathrm{mg}$ P/L, respectively.

\section{Conclusions}

Flow injection on-line digestion is a rapid method for the determination of total phosphorus in beer samples. The entire procedure, from digestion to determination, can be concluded in about 7 or $8 \mathrm{~min}$, compared to many hours for manual digestion methodologies. In addition, it offers safer conditions and saving of laboratory space and staff time.

The UV/thermal induced digestion procedure gave recoveries greater than $90 \%$ for all compounds tested, yielded results comparable to those of conventional digestion methods and showed good precision.

The results obtained in this work and the versatility of the flow injection system suggests that this approach may be suitable for on-line monitoring applications, and allows to assume its applicability to the determination of TP in other matrices.

Acknowledgements The authors gratefully acknowledge collaboration from the brewery UNICER, SA, Leça do Balio, Portugal. One of us (S. M. V. Fernandes) thanks the finantial support from JNICT (grant BD/2851/93-IF).

\section{References}

1. Boyles S (1992) ASBC Journal 50:61-63

2. Broberg O, Persson G (1988) Hydrobiologia 170:61

3. APHA (1990) Standard methods for the examination of water and waste water, American Public Health Association, Washington DC, USA

4. Instituto de Racionalización y Normalización del Trabajo (1994) Metodos oficiales de analisis de los alimentos, AMV Ediciones Mundi-Prensa, Madrid, Spain

5. AOAC International (1997) Official methods of analysis (16th ed) AOAC International, Maryland, USA

6. Benson R, McKelvie I, Hart B (1994) Anal Chim Acta 291: 233-242

7. Woo L, Maher W (1995) Anal Chim Acta 315: 123-135

8. Benson R, McKelvie I, Hart B, Truong Y, Hamilton I (1996) Anal Chim Acta 326:29-39

9. Karlberg B, Pacey GE (1989) Flow injection analysis - A practical guide, Elsevier, BV Amsterdam, The Netherlands, pp 156159

10. Lima JLFC, Rangel AOSS (1990) J Int Sci de la Vigne et du Vin 24:49-61

11.Zagatto EAG, Arruda MAZ, Jacintho AO, Mattos IL (1990) Anal Chim Acta 234:153-160

12. International Union of Pure and Applied Chemistry-IUPAC (1976) Anal Chem 48:2294-2296

13. Miller JC, Miller JN (1993) Statistics for analytical chemistry (3rd ed), Ellis Horwood, Chichester, UK 